\title{
Fisiopatología del asma: una mirada actual
}

\section{Pathophysiology of asthma: a present-day outlook}

RICARDO DURÁN A., MD. ${ }^{(1)}$

\section{Resumen}

El asma es una enfermedad heterogénea y compleja en constante evolución, ahora hablamos de fenotipos moleculares que van cambiando lentamente su enfoque diagnóstico y terapéutico e identificando nuevos blancos para las herramientas farmacológicas en desarrollo.

Existen factores del huésped que predisponen a los pacientes a desarrollar la enfermedad, factores ambientales y situaciones clínicas que favorecen o agravan el asma.

Se describe la cascada inmunológica con los eventos individuales que llevan al desarrollo del asma y las características de la respuesta inmune en el asma severa además de la remodelación de la vía aérea.

Palabras clave: asma, fenotipos moleculares del asma, linfocitos TH1, linfocitos TH2, eosinófilos, asma severa, remodelación de la vía aérea.

\begin{abstract}
Asthma is a constantly evolving, heterogeneous, and complex disease. We now talk about molecular phenotypes that have slowly changed its diagnostic and therapeutic approach; these phenotypes identify new targets for pharmacologic tools currently under development.

There are host factors that predispose patients to develop the disease, as well as environmental factors and clinical situations that favor the appearance or worsening of asthma.

We describe the immunological cascade with the individual events that lead to the development of asthma, and the characteristics of the immune response in severe asthma, plus the remodeling of the airway.
\end{abstract}

Keywords: asthma, molecular phenotypes of asthma, TH1 lymphocytes, TH2 lymphocytes, eosinophils, severe asthma, remodeling of the airway.

\section{Introducción}

El asma se presenta cada vez más, como una situación clínica de heterogenia y complejidad extremas (1).

A medida que se conocen los mecanismos biológicos de esta patología y los diferentes fenotipos moleculares que participan en ella, se ha podido cambiar, si bien de manera lenta, su enfoque diagnóstico y terapéutico (1), y han comenzado a vislumbrarse alternativas farmacológicas que reforzarán el armamento terapéutico, hasta ahora disponible para tratarla.

\section{Factores de riesgo}

Existen factores del huésped que predisponen a que los pacientes manifiesten esta enfermedad. En primer lugar se expresa de base una susceptibilidad genética, con controles poligénicos, aun no aclarados totalmente, en la
(1)Internista, Neumólogo, Unidad de Neumología, Hospital de San José. Bogotá, Colombia.

Correspondencia: Ricardo Durán A., correo electrónico: rimacada@hotmail.com Recibido: $15 / 05 / 15$. Aceptado: 25/05/15. 
que un grupo importante de individuos presenta un componente atópico que favorecerá la producción de inmunoglobulina E (IgE) (2-5). Por otra parte, y siguiendo la misma línea, se presenta susceptibilidad a la diferenciación celular de linfocitos $T$ ayudadores tipo 2 (TH2), en la que se favorece la liberación de mediadores y señales químicas que caracterizan y definen la enfermedad.

Existen factores de riesgo ambientales, que en aquellos individuos susceptibles se convierten en disparadores o iniciadores de la enfermedad. Es así como cierto tipo de infecciones virales respiratorias, que a temprana edad son causantes de cuadros agudos como bronquiolitis, croup, o infecciones del tracto respiratorio inferior como el virus sincitial respiratorio, terminan una vez superada la infección aguda, generando como secuela cuadros típicos de asma (610) (figura 1).

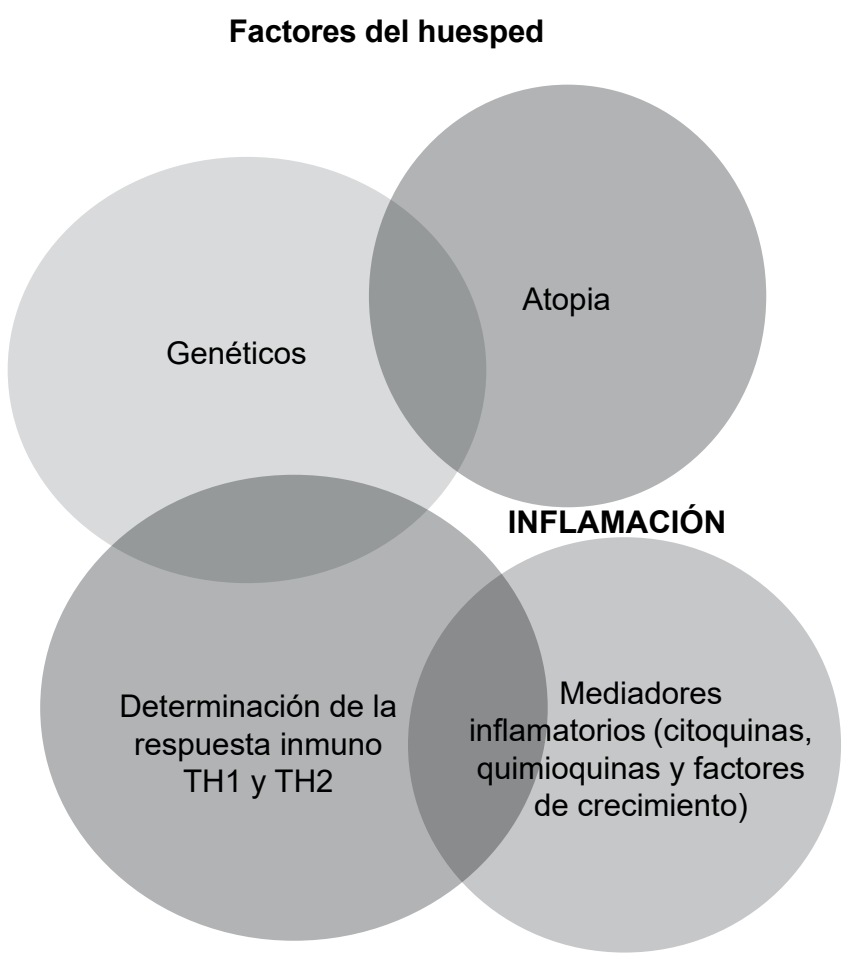

Figura 1. Inflamación como resultado final de una serie de situaciones que confluyen, al unísono, favorecidos por susceptibilidades propias del huésped, donde la genética cumple un papel importante como lo hace en gran parte de las patologías del ser humano.
Por otra parte, se ha visto mayor prevalencia de cuadros alérgicos en niños usualmente citadinos, con "inusuales" ambientes domésticos altamente higiénicos, libres de bacterias o residuos orgánicos que impiden la exposición a los mismos a tempranas edades de la vida (hipótesis higienista), y que al generarse una exposición posterior a estos ambientes (granjas, fincas, animales, etc.) se convierten en disparadores del componente atópico de estas enfermedades, entre ellas las formas alérgicas de asma (9).

Otras exposiciones ambientales, por ejemplo áreas con alto nivel de contaminación del aire por polución, o ambientes laborales con exposición a químicos o gases tóxicos o cigarrillo, pueden generar incrementos locales tisulares de estrés oxidativo, favorecer y estimular la inflamación y la lesión bronquial, y beneficiar la respuesta exagerada de la vía aérea a los alergenos y a las noxas respiratorias (11).

Es evidente que la exposición ambiental a diferentes noxas, sean de origen infeccioso, químico, irritativo, alérgico o de cualquier otro, en individuos susceptibles puede llevar a activar las células epiteliales, las cuales expresan sobre su superficie una serie de receptores de patrón de reconocimiento a señalizaciones dañinas como los patrones asociados a moléculas patógenas (PAMP), los receptores tipo Toll (TLR) (12), o los receptores endógenos para alarminas como ácido úrico y adenosín trifosfato, que son moléculas de señalización de daño, que finalmente estimulan la liberación por parte del epitelio respiratorio de una serie de sustancias que se mencionarán más adelante, y que inician de cierta forma la llamada cascada inmunológica del asma (13).

Existen situaciones clínicas que favorecen o agravan los cuadros asmáticos, por ejemplo la rinitis alérgica (situación obvia entendiendo el tracto respiratorio como uno solo), el reflujo gastroesofágico, la sinusitis crónica, la poliposis nasal y la obesidad; el papel de esta última situación clínica en el asma no es muy claro $(19,20)$.

\section{Inicio de la cascada inmunológica}

En la normalidad, las células dendríticas realizan la vigilancia inmunológica; poseen una vida media corta, lo cual lleva a que se genere una respuesta 
inmunológica relativamente leve, cuando hay, por ejemplo, una exposición alergénica y se da la presentación antigénica a los linfocitos $\mathrm{T}$, los cuales guardarán esa memoria inmunológica y generarán ante una segunda o tercera exposición a la noxa, mecanismos de defensa que intentarán controlar la agresión, sin que se genere una respuesta exagerada (11).

Por otra parte, en el asma, las células dendríticas tienen una vida media más larga, situación que es favorecida por el factor de crecimiento granulocitomacrófago (GMCF) que se encuentra en el sobrenadante epitelial respiratorio. Este fenómeno lleva a que se exceda la respuesta inmunológica, y haya una respuesta inflamatoria marcada en la lámina basal y la mucosa respiratoria (8-11).

$\mathrm{Al}$ exponerse a una noxa, el epitelio respiratorio se ve lesionado, hecho que conduce a la liberación de citocinas proinflamatorias como la interleucina 5 (IL-5), IL-13, IL-25, IL-33, la linfopoyetina tímica estromal (TSLP), el óxido nítrico $(\mathrm{ON})$ y la periostina (estos dos últimos se usan en clínica como indicadores del proceso inflamatorio eosinofílico en la vía aérea), elementos celulares y moleculares que, en conjunto con las células dendríticas, serían los iniciadores probables de la cascada inmunológica en el asma.

\section{Respuesta linfocitaria (activación TH2)}

Una vez comienza la cascada de presentación y activación inmunológica mencionada, inicia la participación activa de los LTH2, los cuales liberan IL-13 e IL-4 y favorecen la diferenciación celular, así como la activación de los linfocitos B (LB). De este modo, emprendan una producción importante de $\operatorname{IgE}$, que ante una exposición alergénica es liberada por estas células y es depositada sobre la superficie de mastocitos provistos de receptores específicos para la IgE. Así, se estimula la liberación de histamina por parte de las células mastocitarias, prostaglandina D2 (PGD2), leucotrienos y quimasas, mediadores químicos, que tienen efecto directo sobre el músculo liso bronquial (el cual había sido previamente sensibilizado por la IL-6 liberada por los LTH2 y macrófagos alveolares (MA) para responder activamente y favorecer la hiperreactividad bronquial) y generar contracción de sus fibras musculares. Por otra parte, la histamina liberada favorece la permeabilidad capilar y el edema de la mucosa bronquial, hallazgos característicos en las vías respiratorias del paciente asmático.

La importancia de la PGD2 liberada por los mastocitos, es su capacidad para estimular directamente a los LTH2 y a los eosinófilos (13), ya que por una parte incrementa su concentración en el tracto respiratorio y por otra disminuye la apoptosis de estas células, fenómeno que perpetúa aún más el componente inflamatorio, favoreciéndose así el componente de cronicidad de la enfermedad.

\section{Respuesta eosinofílica}

La liberación de IL-5 por parte de los LTH2, genera señalización en la médula ósea con el fin de estimular la producción de eosinófilos, los cuales esperarán el "llamado molecular" por parte de los MA activados durante esta respuesta inmunológica, liberando el factor activador de plaquetas (PAF), que a su vez estimulará la migración de los eosinófilos hacia el tracto respiratorio, donde encontrarán las llamadas moléculas de adhesión intercelular e intervascular (ICAM/VCAM), cuya función principal es abrir la "puerta" para el ingreso de estas células a la mucosa respiratoria, la cual será infiltrada e inflamada de manera importante por este grupo celular.

Al entrar en contacto con estas inmunoglobulinas, los eosinófilos, que tienen receptores tanto para $\mathrm{IgE}$ como para $\mathrm{IgG}$, liberarán una serie de sustancias proinflamatorias, dentro de las cuales se encuentran la proteína básica mayor (PBM), leucotrienos y la proteína catiónica eosinofílica, IL-4 e IL-6. Las primeras tres potenciarán aún más el componente de broncoespasmo, estimularán la fase inflamatoria y, por otra parte, favorecerán con el paso del tiempo la fibrosis peri-bronquial y la remodelación de la vía aérea.

Por su parte, las interleucinas liberadas continuarán su efecto ya mencionado previamente, estimulando a los linfocitos B para elevar la producción de inmunoglobulinas, mientras que la IL-6 estimulará al músculo liso bronquial para incrementar el componente hiperreactivo. 


\section{Receptores nerviosos}

En la medida en que se genera el daño epitelial, concomitantemente con el "despulimiento" de la mucosa bronquial, quedan expuestas una serie de terminaciones nerviosas de los sistemas peptidérgico, colinérgico y adrenérgico, situaciones que modulan en cierta forma el tono de la vía aérea; estas terminaciones quedan fácilmente expuestas a ser estimuladas por las diferentes citocinas, y adicionalmente poseen receptores peptídicos que responden con rapidez al estímulo de taquiquininas, neuropéptidos tipo sustancias A y sustancia $P$, que agravan la extravasación vascular, favorecen la vasodilatación, estimulan la secreción glandular, e incrementan de esta forma el componente inflamatorio favoreciendo la contracción del músculo liso bronquial.

\section{Asma severa: respuesta inmune diferente (No TH2)}

Dentro del amplio espectro clínico del asma, cerca de un $10 \%$ de los pacientes, tiene un comportamiento clínico diferente a lo habitualmente visto, puesto que no responden en forma adecuado a dosis plenas de corticoides inhalados asociados a terapia broncodilatadora de larga acción con otros controladores y presentan exacerbaciones a pesar de estar bajo tratamiento, crisis que con frecuencia requieren de atención hospitalaria $(15,16)$. Desde el punto de vista funcional, en este grupo de pacientes existe un componente obstructivo importante, como resultado de una inflamación eosinofílica persistente, asociada a remodelación de la vía aérea (8).

Estos cuadros de asma no controlada severa, probablemente están asociados a mecanismos fisiopatológicos que envuelven elementos y actores participantes algo distintos a los mencionados hasta ahora; por otro lado, se aprecia que cuando los participantes son los mismos, pareciera incrementar la actividad de alguno de estos actores dentro de la fisiopatología del asma. Un ejemplo de esta situaciones cuando la prostaglandina D2 comienza a incrementar su actividad estimulante sobre linfocitos TH2 y eosinófilos, para disminuir la apoptosis celular de los últimos y estimular la acción de los primeros, perpetuando e incrementando el componente inflamatorio tisular.
A diferencia de las formas habituales y alérgicas de la enfermedad en las que predomina la vía de activación de los LTH2 con la consecuente participación de eosinófilos, en el paciente severo se activan vías distintas a partir de linfocitos tipo TH1, TH17 con participación de los neutrófilos. Aquí la respuesta inmune tipo 1 , involucra a otros actores, por ejemplo producción de interleucina IL-17, IL17A, IL-17F (línea celular TH17) y activación de LTH17, linfocitos CD4, CD8 y células NK.

Estas interleucinas señalizan a través de receptores para generar la liberación de factores proinflamatorios tales como IL-6 e IL-8, estimulando de manera importante el componente hiperreactivo muscular; si bien hasta el momento no hay claridad sobre el posible estímulo para la participación y la activación de neutrófilos, está en consideración una asociación entre IL-17 y la activación de este grupo celular, con aumento de la producción de elastasas, catepsinas $\mathrm{G}$ y metaloproteinasas.

En las biopsias de tejido bronquial de pacientes con asma severa se ha encontrado inflamación granulomatosa, y no ha sido posible dilucidar si corresponde a una complicación del asma en su forma severa, $o$ si es secundaria a la terapia farmacológica (21).

\section{Remodelación de la vía aérea en asma}

Aunque la mayoría de pacientes asmáticos suele presentar formas de asma que muestran reversibilidad funcional, en los estados intercríticos un grupo importante presenta, en cuanto al componente funcional, obstrucción no reversible completa, que puede explicarse por la remodelación de la vía aérea.

Esta alteración estructural es el resultado de cambios epiteliales, en la membrana basal, la submucosa, el músculo liso bronquial y los vasos sanguíneos de la pared bronquial y bronquiolar, como respuesta al estímulo inflamatorio prolongado (14). Dichos cambios incluyen despulimiento y daño del epitelio respiratorio, depósito de colágeno maduro y fibrosis subepitelial, aumento de la masa muscular, concomitantemente con incremento en el número de miofibroblastos, depósito de matriz extracelular y neovascularización, que se traducen 
en engrosamiento y fibrosis periluminal, y por ende en obstrucción de las vías aéreas que lleva a una pérdida del retroceso elástico, hiperinsuflación e irreversibilidad o reversibilidad parcial con terapia broncodilatadora (5-7).

\section{Conflictos de interés}

El autor declara no tener conflictos de interés.

\section{Bibliografía}

1. Global Strategy for Asthma Management and Prevention, Global Initiative for Asthma (GINA) 2015. http://www.ginasthma.org/ [Acceso 23 May 2015).

2. Stone KD, Prussin C, Metcalfe DD. IgE, mast cells, basophils, and eosinophils. J Allergy Clin Immunol. 2010;125:S73.

3. Salo PM, Calatroni A, Gergen PJ, et al. Allergy-related outcomes in relation to serum IgE: results from the National Health and Nutrition Examination Survey 2005-2006. J Allergy Clin Immunol. 2011;127:1226.

4. Kaan A, Dimich-Ward H, Manfreda J, et al. Cord blood IgE: its determinants and prediction of development of asthma and other allergic disorders at 12 months. Ann Allergy Asthma Immunol. 2000;84:37.

5. Oettgen HC, Geha RS. IgE regulation and roles in asthma pathogenesis. J Allergy Clin Immunol. 2001;107:429.

6. James AL, Elliot JG, Abramson MJ, Walters EH. Time to death, airway wall inflammation and remodelling in fatal asthma. Eur Respir J. 2005;26:429.

7. Gelb AF, Schein A, Nussbaum E, et al. Risk factors for nearfatal asthma. Chest. 2004;126:1138.

8. Miranda C, Busacker A, Balzar S, et al. Distinguishing severe asthma phenotypes: role of age at onset and eosinophilic inflammation. J Allergy Clin Immunol. 2004;113:101.

9. Von Ehrenstein OS et al: Reduced risk of hay fever and asthma among children of farmers. Clin Exp Allergy. 2000;30:187-93.

10. Sigurs N, Gustafsson PM, et al. Severe respiratory synsytial virus bronchiolitis in infancy and asthma and allergy at age 13 . Am J Respir Crit. Care Med. 2005;171;137-41.

11. Jahnsen FL, Moloney ED, Hogan T, et al. Rapid dendritic cell recruitment to the bronchial mucosa of patients with atopic asthma in response to local allergen challenge. Thorax. 2001;56:823.

12. Wong CK, Cheung PF, Ip WK, Lam CW. Intracellular signaling mechanisms regulating toll-like receptor-mediated activation of eosinophils. Am J Respir Cell Mol Biol. 2007;37:85.

13. Xue L, Gyles SL, Wettey FR, et al. Prostaglandin D2 causes preferential induction of proinflammatory $\mathrm{TH} 2$ cytokine production through an action on chemoattractant receptor-like molecule expressed on TH2 cells. J Immunol 2005; 175:6531.

14. Berry M, Morgan A. Shaw DE et al. Pathological features and inhaled corticosteroid response of eosinophilic and non eosinophilic asthma. Thorax 2007;62:1043-9.

15. Chung KF, Wenzel SE, Brozek JL, et al. International ERS/ ATS guidelines on definition, evaluation and treatment of severe asthma. Eur Respir J. 2014;43:343.

16. Moore WC, Meyers DA, Wenzel SE, et al. Identification of asthma phenotypes using cluster analysis in the Severe Asthma Research Program. Am J Respir Crit Care Med. 2010;181:315.

17. Moore WC, Hastie AT, Li X, et al. Sputum neutrophil counts are associated with more severe asthma phenotypes using cluster analysis. J Allergy Clin Immunol. 2014;133:1557.

18. Moore WC, Hastie AT, Li X, et al. Sputum neutrophil counts are associated with more severe asthma phenotypes using cluster analysis. J Allergy Clin Immunol. 2014;133:1557.

19. Burgess JA, Walters EH, Byrnes GB, et al. Childhood allergic rhinitis predicts asthma incidence and persistence to middle age: a longitudinal study. J Allergy Clin Immunol. 2007; $120: 863$.

20. Beuther DA, Sutherland ER. Overweight, obesity, and incident asthma: a meta-analysis of prospective epidemiologic studies. Am J Respir Crit Care Med. 2007;175:661.

21. Wenzel SE, Vitari CA, Shende M, et al. Asthmatic granulomatosis: a novel disease with asthmatic and granulomatous features. Am J Respir Crit Care Med. 2012;186:501. 